\title{
Antidepressants and human memory: an investigation of four drugs with different sedative and anticholinergic profiles
}

H. Valerie Curran, Mingquan Sakulsriprong, and Malcolm Lader

Department of Psychiatry, Institute of Psychiatry, De Crespigny Park, London SE5 8AF, UK

Change scores depicted in Fig. 1 are inaccurate - correct means for free recall are given in the adjacent Table 3.

Table 3 contains 2 errors: column 13, line 4 should be 25.7 not 15.7; column 5 line 11 should be 4.1 not 41 . Figure $4 \mathrm{a}$ depicts mean number of lines of letters cancelled and Fig. $4 \mathrm{~d}$ depicts means for correct responses in the reaction time task. 